\title{
Acquisition and maintenance of Sidman avoidance with paired rat subjects
}

\author{
WILLIAM L. CUNNINGHAM, JR.* and ALBERT E. ROBERTS $\dagger$ \\ Catawba College, Salisbury, North Carolina 28144
}

\begin{abstract}
Rat Ss were used to study the acquisition and maintenance of Sidman avoidance as a function of either single or paired training. Ss receiving paired training failed to acquire the leverpress response even after a block of individual training sessions. Within the paired training condition, Ss that were housed separately evidenced better acquisition than Ss housed as pairs. When Ss that were efficiently avoiding under individual training conditions were paired, avoidance was severely disrupted.
\end{abstract}

It is well documented that the behavior of an $\mathrm{S}$ can be substantially altered if a second $S$ is introduced into the training situation. For example, increases in performance (social facilitation) have been reported for consummatory responses (Smith \& Ross, 1952), locomotor behaviors (Simmel, 1962; Hughes, 1969), and conditioned suppression responding (Hake \& Laws, 1967).

On the other hand, decreases in performance (social inhibition) have also been observed, especially when electric shock is used as the reinforcer (but see Zajonc, 1966 , for nonshock events). Social inhibition has been reported for responding under escape (Ulrich, 1967), discriminated avoidance (Logan \& Boice, 1968), and Sidman avoidance (Davis, 1969) schedules.

Some theorists (cf. Zajonc, 1965) have suggested that the effects of pairing Ss in the training situation will be different depending on whether the acquisition, or the performance, of a response is being examined. Specifically, during acquisition, when the response to be learned is not dominant, the presence of a second $S$ will inhibit acquisition; after the response has been acquired, and thus is dominant, the second $S$ will facilitate the performance (see Weiss \& Miller, 1971, for an extension of this position).

Such an analysis has received support with human Ss trained under Sidman avoidance schedules. Ader and Tatum (1963) reported that singly trained Ss acquired the avoidance response in less time than yoked pairs, which were in visual contact with each other. But following acquisition, the yoked pairs showed greater responding than the singly trained Ss. The Ader and Tatum (1963) result conflicts with the results of Davis (1969), who used rat Ss. Davis (1969) reported impairment of Sidman avoidance performance both when two trained Ss were paired and when a trained $S$

* Now at lowa State University, Ames, Iowa 50010.

$\doteqdot$ Requests for reprints should be sent to Albert E. Roberts, Department of Psychology, Catawba College, Salisbury, North Carolina 28144. and a naive $S$ were paired. A cursory review of the literature indicated that the acquisition of Sidman avoidance with paired animal Ss has not yet been examined. It was decided to study the acquisition of Sidman avoidance using the procedures employed by Davis (1969). The first purpose of this experiment was to study Sidman avoidance acquisition as a function of training, paired vs single. Within this condition, acquisition was also examined as a function of S's housing assignment, paired vs individual. The second purpose was to examine changes in avoidance performance as a function of training, paired vs single.

\section{METHOD}

\section{Subjects and Apparatus}

Twelve female hooded rats, purchased from Blue Spruce Farms, New York, served as Ss. Ss were experimentally naive, had a mean weight of $128 \mathrm{~g}$, and were about 6 weeks old at the beginning of experimentation.

A standard single-lever Lafayette operant chamber (Model 84031 ) was modified by removing food and water reinforcement delivery systems and adding a houselight in the center of the ceiling. The lever, metal sides, and grid floor were wired in series to a shock generator (BRS SG-901) and scrambling device (BRS SC-901). Experimentation occurred in a sound-attenuated room, with relay programming equipment housed in an adjoining sound-attenuated room.

\section{Housing}

Ss were shipped as a group from the supplier and randomly assigned to one of several housing-training conditions upon arrival: four $S$ s were housed singly and the remaining eight Ss housed as pairs. Prior to training, S 1 and S 2 had been housed singly for 5 days, S 3 and S 4 housed singly for 26 days, and the remaining Ss housed as pairs (Pairs 1, 2, 3, and 4) for 25 days. One member of each pair was marked on the tail for identification purposes. All Ss had food and water continuously available.

\section{Training}

A free operant avoidance procedure (Sidman, 1953) was in effect during the entire experiment. A leverpress postponed shock for $15 \sec (\mathrm{R}-\mathrm{S}=15)$ and briefly turned off the 


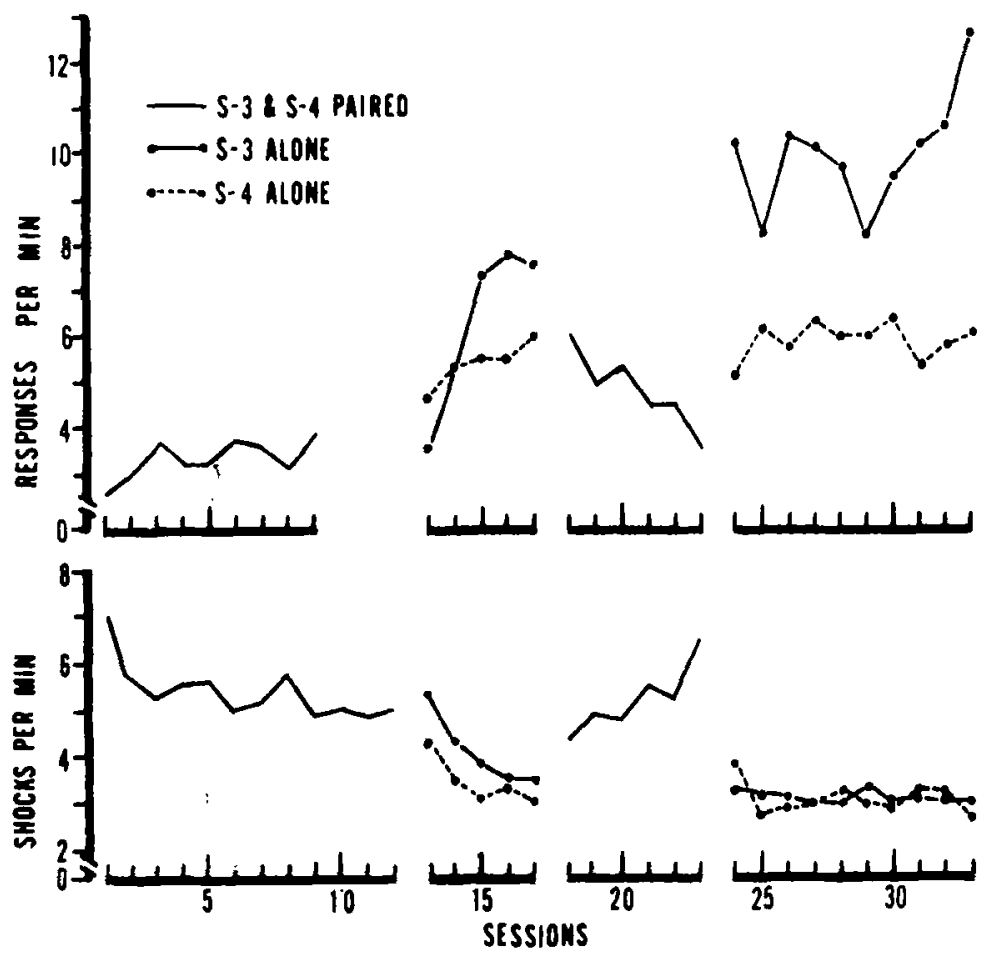

houselight, the only source of illumination in the room. Failure to respond resulted in a $.5-\mathrm{sec} 1-\mathrm{mA}$ shock delivered every $5 \mathrm{sec}$ $(\mathrm{S}-\mathrm{S}=5)$. All sessions lasted $1 \mathrm{~h}$ and, except during Phase 2 , were given daily. The experiment was run in four phases according to the specifics of the training conditions.

\section{Plase 1}

The singly housed Ss were trained either singly ( $\mathrm{S} 1$ and $\mathrm{S} 2$ ) or as a pair ( $S 3$ and $S 4$ ). The $S$ s housed as pairs were trained as pairs. $S 1$ and $S 2$ received single training until Phase 4 , i.e.. 26 sessions. $S 3$ and $S 4$ received 12 sessions, while Pairs 1, 2. 3. and 4 received 8 sessions of training under Plase 1 .

\section{Phase 2}

All Ss trained as pairs in Phase 1 received five sessions of individual training. Sessions were given on alternate days under this phase.

Phase 3

The paired training conditions of Phase 1 were reinstated for S 3 and $S 4$ (five sessions) and Pairs 1, 2, 3, and 4 (six sessions).

Phase 4

S 3 and S 4 received 10 individual training sessions, i.e., a repeat of Phase $2 . S 1$ and S 2 were given 5 paired training sessions.

Phase 1 examined Sidman avoidance acquisition as a function of the conditions of training (paired vs single) and, within the paired training condition, as a function of housing. Phase 3 examined changes in performance under paired training following a period of individual training (Phase 2). Phase 4 examined changes in performance when singly trained $S_{s}$ ( $S$ I and $S 2$ ) received paired training.

During all phases of the experiment, response and shock frequencies were counted. One E (W.L.C.) was frequently present in the sound-attenuated room to make informal observations about Ss' behaviors and. whenever possible, to note which member of the pair emitted lever responses. respectively.
Fig. 1. Response and shock rates for $\mathrm{S} 3$ and $S 4$ for each session under paired training (Phases 1 and 3) and single training (Phases 2 and 4).

\section{RESULTS}

A determination of Sidman avoidance acquisition is a relative concept which is often based on a point of performance along a continuum. For example, $S$ may not emit any responses and remain in the S.S interval: if this were the case. $\mathrm{S}$ would receive about 12 shocks/min in this experiment. S could respond only to the delivery of shock and receive about 4 shocks/min. Shock rates less than $4 / \mathrm{min}$ would indicate that $S$ was responding to postpone shock; the lower the shock rate, the more frequently $S$ would emit shock postponement responses.

\section{Acquisition: Paired vs Single Training}

The five pairs (including S 3 and S 4) failed to acquire the avoidance response. Figure 1 presents sessional response and shock rates for $\mathrm{S} 3$ and S 4 and shows that in Phase 1. this pair responded mainly to shock, i.e., receiving about 5.1 shocks $/ \mathrm{min}$. On the other hand, Pairs $1,2,3$, and 4 responded infrequently and showed shock rates of about 12/min (Pair 2 about 8.7 shocks/min).

S 1 and S 2, which were housed and trained singly, showed a continuous reduction in shock rate and increase in response rate over Phase 1 sessions. Figure? presents the number of responses and shocks per minute for each $S$ over the final 10 sessions of Phase 1 and shows that a majority of shocks were being postponed. Phase 1 was terminated after fewer sessions for the paired Ss, but over periods comparable to the paired Ss. $\mathrm{S} 1$ and $\mathrm{S} 2$ were showing shock rates of about 1.3 and 2.9 and response rates of about 15.7 and 8.1.

In Phase 2, the members of Pairs 1. 2. 3. and 4 received five sessions of individual training. Only three 
of the eight Ss acquired the leverpress response, but only to escape shock. When the Ss were paired again in Phase 3. responding continued to be infrequent for Pairs 1 and 4; Pairs 2 and 3 showed some evidence of shock-elicited responding, i.e., shock rates of about $7 / \mathrm{min}$ and response rates of about $3.5 / \mathrm{min}$.

\section{Avoidance Acquisition and Housing}

The results presented above for the paired-training condition suggest that housing may have been a factor. Pairs 1. 2, 3, and 4 were housed and trained together in Phase 1 and evidenced little leverpressing. Over the eight Phase 1 sessions, Pair 1 emitted a total of 8 responses; Pair 2. 617 responses, Pair 3, 140 responses; and Pair 4, 100 responses. S 3 and S 4 were trained together but housed separately and emitted a total of 1,401 responses over the first eight sessions. These Ss responded primarily to shock rather than to postpone shock; the four pairs, on the other hand, spent a large proportion of each session in the S-S interval.

\section{Maintenance: Pair vs Single Training}

Figure 1 shows that when S 3 and $\mathrm{S} 4$ received individual training, responding increased and shock frequencies decreased compared to Phase 1. When paired again in Phase 3, responding decreased and shock frequency increased; both measures matched the levels obtained under Phase 1 . A return to individual training (Phase 4) again produced improved performance.

$\mathrm{S} 1$ and S 2 received 26 sessions of individual training and, as Fig. 2 shows, were reliably avoiding shock rather than responding to shock (as was the case for S 3 and S 4). The Ss received five sessions of paired training. That avoidance was immediately impaired, and worsened over sessions, can be clearly seen in the shock rate data of Fig. 2. Over the final sessions of Phase 1, Ss showed individual shock rates less than 1.0. By the final session of Phase 4, shock rate for the pair had increased to 4.0 .

\section{Behavioral Observations}

During Phase 1, Pairs 1, 2, and 3 often sparred (clawing, postural threats, head lunges), although physical contact during sparring was infrequent. When not sparring, the pairs huddled together close to the lever. The sparring seemed to have three features. First, it occurred only during shock. Second, it occurred when Ss were in relatively close proximity and facing each other. That is, if the Ss were separated by the distance of the chamber, they would not approach each other to spar. Third, the occasional lever responses occurred as a result of shock: When sparring near the lever, one $S$ would fall on the lever. One outcome of sparring often observed was that one S would "win" by forcing his partner down on the grids; the "winner" would huddle on top of the downed "loser." Neither locomotor
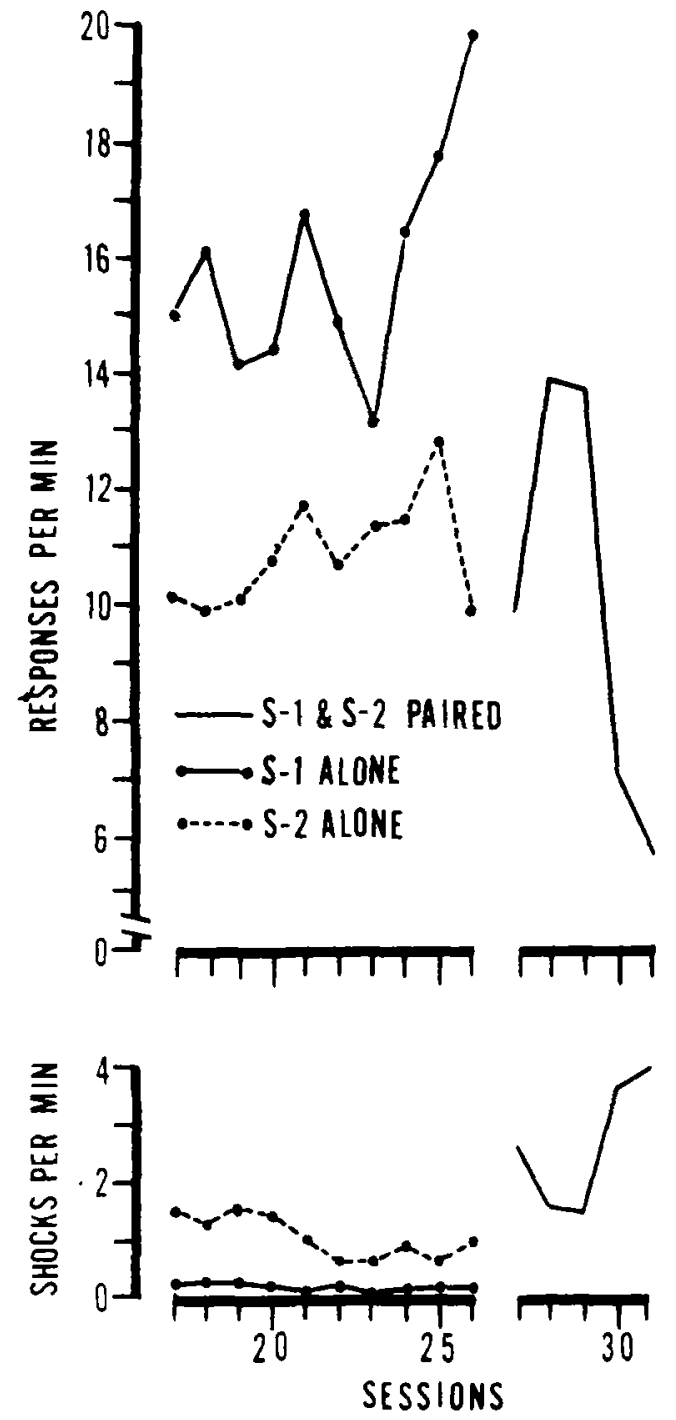

Fig. 2. Response and shock rates for $S 1$ and $S 2$ over the final 10 sessions of individual training (Phase 1) and the 5 sessions of paired training (Phase 4).

activity, such as exploration, nor grooming was observed during shock-free periods.

S 3 and S 4, in contrast to Pairs 1, 2, 3, and 4, showed less sparring and more grooming (self-grooming and grooming of the other) in Phase 1. Most of the lever responses $(79 \%)$ were emitted by $\mathrm{S} 3$, which subsequently showed greater responding in the individual sessions (see Fig. 1). S 3 frequently held down the lever while $S 4$ leaned across S 3's back.

In Phase 4, grooming was prominent for S 1 and S 2 over the first two sessions but was replaced by an increasing incidence in sparring and aggression (physical contact during sparring). In fact, the final session was prematurely terminated as a result of S l's biting $S 2$ behind the ear to produce profuse bleeding. Ss would begin a session huddled by the lever and emit shock-postponement responses, while S 2 went to the back of the chamber. The Ss would again huddle, and 


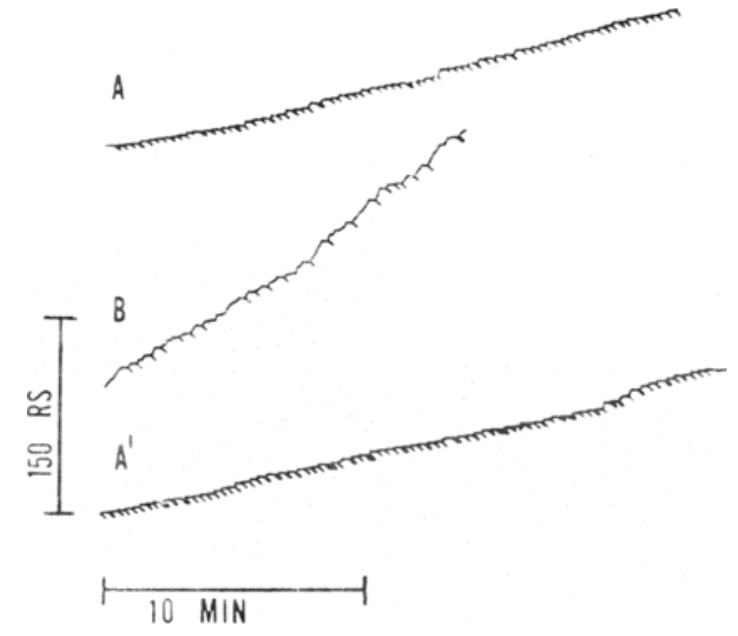

Fig. 3. The cumulative response record for $S 1$ and $S 2$ taken from the fourth session of paired training (Phase 4). Part $A$ was obtained when Ss huddled by the lever, Part B during a "natural" separation, and Part A' when huddling reinstated.

shock-elicited responding reappeared. Figure 3 presents a cumulative response record from the fourth session of Phase 5 which illustrates the differential avoidance during the session. Part A shows avoidance behavior when Ss huddled by the lever (the first $22 \mathrm{~min}$ ). Part B shows avoidance during a 14-min "natural" separation: note that the number of shocks celivered decreased while responding increased. Part $A^{\prime}$ is a "natural" within-session replication of Part A when Ss once again huddled by the lever. The remainder of the session ( 24 min) was characterized by shock-elicited responding.

\section{DISCUSSION}

Twelve rats were used to study the acquisition and maintenance of Sidman avoidance as a function of training, single vs paired. The results of the experiment indicated that Ss housed and trained as pairs failed to acquire the leverpress response. A block of individual training sessions did not result in improved performance when Ss were again trained as pairs. These pairs did not learn to respond even though a feedback stimulus was present that should have favorably affected response acquisition (cf. Bolles \& Popp, 1964). The two singly trained Ss, on the other hand, learned to postpone shock. This result is typically reported whether Ss are housed individually or under grouped conditions.

Second, the pair housed separately (S 3 and S 4) evidenced better response acquisition than the pairs that were housed together. But, this pair responded primarily to shock rather than to postpone shock. Thus, this result suggests that the conditions of housing may be important and merit additional experimentation.

Third, the presence of a second $S$ in the training situation severely disrupted both shock-elicited and shock-postponement responding. With respect to acquisition, these results are similar to the results reported by Ader and Tatum (1963). With respect to performance of the response, these results are opposite to those of Ader and Tatum (1963) but confirm the findings of Dav's (1969). In addition, the present authors agree with the Davis interpretation that the disruption resulted from the frequent instances of social behaviors which competed (i.e., interfered) with leverpressing. The cumulative records in Fig. 3 illustrate the outcome of such competition.

In contrast to the Davis (1969) report, shock-elicited sparring was often observed, particularly for Ss not showing frequent leverpressing, i.e., the pairs. On the other hand, aggression was present for Ss showing efficient avoidance (S 1 and S 2), but was not restricted to shock delivery periods. Finally, in no case were Ss observed to spar or aggress for a "right to respond" on the lever which Davis (1969) had observed.

When not sparring, the paired Ss huddled in positions similar to those described and illustrated by Grant and Mackintosh (1963). Huddling seemed to be the paired-S analogue to the freezing often observed during acquisition in singly trained Ss. Huddling was more characteristic for Pairs 1, 2, 3, and 4 than for S 3 and S 4 when trained as a pair. This difference may have been related to the conditions of housing. That is, dominance relationships (which were not assessed in this experiment) may have been established prior to experimentation (cf. Denny \& Ratner, 1970). The Ss then may have been attempting to escape shock by huddling rather than learning to postpone shock by leverpressing. In any case, the conditions of housing seem to be a consideration important in the design of social facilitation/inhibition experiments.

This study, in which either $S$ had opportunity to respond on the single lever, represents only one of several possible procedures for studying Sidman avoidance acquisition under paired-S conditions. Zajonc (1966) has described two alternative procedures, with one of the two Ss being either a coactor or a spectator. Under the coaction condition, two physically separated Ss are simultaneously engaged in leverpressing. Under the spectator (or audience) condition, one $S$ leverpresses in the presence of a second $S$ not involved in the response requirement. McGinnies (1970) has suggested a third possibility involving a cooperative response requirement, e.g., each $\mathrm{S}$ being required to leverpress to postpone shock. By imposing physical separation while permitting visual contact, behaviors which might interfere with responding, as described above, could be eliminated.

\section{REFERENCES}

Ader, R., \& Tatum, R. Free operant avoidance in individual and paired human subjects. Journal of the Experimental A nalysis of Behavior. 1963,6, 357-359.

Bolles, R. C.. \& Popp. R. J. Parameters affecting the acquisition of Sidman avoidance. Journal of the Experimental Analysis of 
Behavior, 1964, 7. 315-321.

Davis, H. Social interaction and Sidman avoidance performance. Psuchological Record, 1969, 19, 433442.

Denny, M. R.. \& Ratner, S. C. Comparative psychology. (Rev. ed.) Homewood, Ill: Dorsey Press, 1970.

Grant. E. G., \& Mackintosh. J. H. A comparison of the social postures of some rodents. Behaviour, 1963, 21, 246-259.

Hake, D. F., \& Law's, D. R. Social facilitation of responses during a stimulus paired with electric shock. Journal of the Experimental Analysis of Behavior, 1967, 10, 387-392.

Hughes, R. N. Social facilitation of locomotion and exploration in rats. British Journal of Psychology, 1969, 60, 385-388.

Logan, F. A., \& Boice, R. Aggressive behaviors of paired rodents in an avoidance context. Behaviour, 1968, 34, 161-183.

McGinnies, E. Social behavior: A functional analysis. Boston: Houghton Mifflin, 1970.

Sidman, M. Avoidance conditioning with brief shock and no exteroceptive warning signal. Science, 1953, 118, 157-158.

Simmel, E. C. Social facilitation of exploratory behavior in rats. Journal of Comparative \& Physiological Psychology, 1962, 55, 831-833.

Smith, W. I.. \& Ross, S. The social behavior of vertebrates: A review of the literature (1939-1950). Psychological Bulletin, 1952, 49, 598-627.

Ulrich, R. E. Interaction between reflexive fighting and cooperative escape. Journal of the Experimental Analysis of Behavior, 1967, 10, 311-317.

Weiss, R. F., \& Miller, F. G. The drive theory of social facilitation. Psychological Review, 1971, 78, 44-57.

Zajonc, R. B. Social facilitation. Science, 1965, 149, 269-274.

Zajonc, R. B. Social psychology. Belmont. Calif: Brooks/Cole, 1966.

(Received for publication June 22, 1972; revision received August 21, 1972.) 